\title{
Compliance with gestational weight gain recommendations in a cross-sectional study of term pregnancies - how far reality falls from the standard?
}

\author{
Anna Kajdy ${ }^{1}{ }^{\circledR}$, Justyna Sztajerowska² ${ }^{\circledR}$, Katarzyna Muzyka-Placzynska ${ }^{1}(\mathbb{D}$, \\ Jan Modzelewski ${ }^{1}{ }^{\mathbb{D}}$, Dorota Sys ${ }^{1}{ }^{\mathbb{D}}$, Malgorzata Starzec-Proserpio ${ }^{3}{ }^{(D}$, \\ Barbara Baranowska ${ }^{3}$, Dagmara Filipecka-Tyczka ${ }^{1}$, , Michal Rabijewski ${ }^{1}$ (1) \\ ${ }^{1}$ Department of Reproductive Health, Center of Postgraduate Medical Education, Warsaw, Poland \\ ${ }^{2}$ St. Sophia's Specialist Hospital, Warsaw, Poland \\ ${ }^{3}$ Department of Midwifery, Center of Postgraduate Medical Education, Warsaw, Poland
}

\begin{abstract}
Objectives: During pregnancy, two aspects are critical in the context of adverse perinatal outcomes (APO): preconception obesity and gestational weight gain. This study aimed to assess compliance with the 2009 IOM guidelines, compare GWG with and without correcting for gestation duration, and observe the relationship between pre-pregnancy BMI and GWG and neonatal birth weight.

Material and methods: This is a cross-sectional study conducted from 2015-2018 at the St. Sophia's Specialist Hospital in Warsaw, Poland. Self-reported pre-pregnancy and predelivery weight were collected.

Results: The presented data set amounts to 7820 records. Analysis of weight gain compliance with IOM recommendations showed that only $41-44 \%$ (depending on the calculation method) of women had weight gain in accordance with IOM guidelines (22-23\% - below; 33-37\% - above). Overweight and obese women with diabetes are more likely to comply with IOM than women without diabetes. In contrast, women with normal-weight and underweight with diabetes are less likely to achieve IOM weight gain in pregnancy than women without diabetes. Women who have GWG below recommendations significantly more often gave birth to SGA neonates, and women who exceeded GWG standards significantly more often gave birth to LGA neonates.

Conclusions: Less than half of women had GWG within the recommended norms. Statistically significant differences were found in methods of calculation of GWG, but it was not found clinically significant. Correction for pregnancy duration when calculating GWG reclassifies two percent of patients. We underestimate the risk of crossing the line between overweight and obesity during pregnancy.

Key words: pregnancy; gestational weight gain; diabetes, gestational, body mass index, cross-sectional studies; Poland
\end{abstract}

Ginekologia Polska 2021; 92, 12: 884-891

\section{INTRODUCTION}

The World Health Organization (WHO) has named obesity the most dangerous chronic disease of the current times. It is a multifactorial public health concern and a significant challenge of the $21^{\text {st }}$ century. It is vital to acknowledge how maternal weight, diet, and physical activity shapes the intrauterine environment. Epigenetics raised awareness of the potential risks related to environmental factors shaping the following generations' health. Medical costs associated with treating diseases caused by obesity and overweight in 2025 could reach 1.2 billion dollars [1-3].

During pregnancy, two aspects are critical in the context of adverse perinatal outcomes (APO). One is preconception obesity, and the second is gestational weight gain. Both independently increase the risk of infant adiposity, childhood obesity, glucose, insulin, and cardiometabolic dysregulation [4]. 
Already in 1950-1960, the association between weight gain and pregnancy outcome was noted. Previously the recommended gestational weight gain did not exceed $7 \mathrm{~kg}$ and, if present, was associated with a high risk of preeclampsia. That limit was soon found to be insufficient in providing optimal perinatal outcome and was raised to $12 \mathrm{~kg}$. The 1990 Institute of Medicine (IOM) guidelines provided specific recommendations related to pre-pregnancy BMI. With the growing global epidemic of obesity, those guidelines needed revision in 2009 [5]. The primary differences between the two documents were: use of WHO categories of pre-pregnancy Body Mass Index (BMI) instead of Metropolitan Life Insurance Company's ideal, development of ranges for gestational weight gain (GWG) for the second and third trimester. The latter has created specific goals for obese pregnant women. The goal ranged between $5-9 \mathrm{~kg}$, instead of being at least $7 \mathrm{~kg}$. The IOM guidelines are based primarily on observational data of associations $[6,7]$.

Gilmore and Redman have presented a unified method of calculating gestational weight gain [1]. They have drawn attention to the fact that most studies estimate gestational weight gain without adjusting for gestational age. In their study, they compared four methods of calculating gestational weight gain. They showed that by adjusting for gestational age, there was a $40 \%$ increase in the number of cases with defined excess weight gain.

\section{Objectives}

This study's primary aim was to assess compliance with the 2009 IOM guidelines among term Polish pregnant women. We hypothesized that with the growing prevalence of overweight and obesity in Poland, the compliance would be inadequate, primarily among obese women. The secondary aim was to compare two methods of assessing GWG with and without correcting for gestation duration. We hypothesized that adjusting for pregnancy duration in term pregnancies (37-40 weeks) affects the classification of adherence to the IOM guideline. Thirdly we compared adherence to the IOM guideline in two groups with and without gestational diabetes (GDM). We hypothesized that the GDM group has better adherence to the guidelines. Finally, we looked at the relationship between pre-pregnancy BMI, GWG, and neonatal birth weight. We hypothesized that both higher pre-pregnancy BMI and GWG resulted in the birth of larger neonates.

\section{MATERIAL AND METHODS}

This is a cross-sectional study. Data was collected through the electronic database of the St. Sophia's Specialist Hospital in Warsaw, Poland. The study was conducted from 2015-2018. All women at the obstetrics unit are offered a urogynecological consultation before discharge from the postpartum ward. They consented to a urogynecological examination and a brief medical history interview. As part of the survey, self-reported pre-pregnancy and predelivery weight was collected. This data was used for this study. These records were matched with other available patient electronic records, including age, parity, diabetes, hypertension, neonatal birth weight, and delivery mode. This data allowed a description of the demographic characteristics of the studied group.

Inclusion criteria: pregnancy $>37$ weeks (confirmed by LMP and first-trimester ultrasound), consent for an urogynecology examination and medical interview, complete self-reported data on pre-pregnancy and predelivery weight. Exclusion criteria were preterm deliveries, multiple deliveries, incomplete data regarding weight and height, and pregestational diabetes. The study size was established after excluding patients that did not meet eligibility criteria.

Pre-pregnancy and pre-delivery BMI were calculated from weight and height. The formula was weight in kilograms/height in meters squared. According toWHO, each woman in the study group was classified into four BMI groups (Tab. 1).

All data was imputed into a Microsoft Excel 365 calculation sheet (Microsoft Corporation, Redmond, USA).

Gestational weight gain was calculated using two methods described by Gilmore and Redman. Method I is the most used for reporting GWG and adherence to the IOM guidelines. It is calculated by subtracting pre-pregnancy weight (PPW) from the predelivery weight (PDW) and comparing it to the IOM guideline of GWG at 40 weeks (GWG = PPW - PDW). Method II also subtracts pre-pregnancy weight from delivery weight but corrects for gestational age at delivery [GWG $=($ PPW - PDW/GA at delivery $) \times 40$ weeks] . In this case, a weekly average weight gain was calculated by dividing the GWG by the number of pregnancy weeks at delivery. The average weekly weight was multiplied by 40 weeks and compared to the IOM at 40 weeks.

Women were classified as adhering, being above or below IOM GWG guidelines by the two calculation methods (method I and method II). The calculations were made for the whole population and divided into two groups with and without gestational diabetes. Differences between classifications by the two methods depending on the pre-pregnancy BMI group were compared and analyzed. Secondly, the analysis was performed in two groups with and without gestational diabetes.

The outcomes analyzed were number of women in each pre-pregnancy weight category, the number of women adhering to IOM guidelines depending on the method used for GWG and pre-pregnancy BMl; differences in adherence to IOM guidelines in women with and without gestational diabetes; effect of pre-pregnancy BMI and GWG on neonatal birth weight. Centiles for neonatal birthweight were 
Table 1. Institute of Medicine recommended weight gain recommendations

\begin{tabular}{|l|l|l|}
\hline Prepregnancy weight category & Body mass index & Recommended range of weight gain [kg] \\
\hline underweight & Less than 18.5 & $12.5-18$ \\
\hline Normal Weight & $18.5-24.9$ & $11.5-16$ \\
\hline Overweight & $25-29.9$ & $7-11.5$ \\
\hline Obese (includes all classes) & 30 and greater & $5-9$
\end{tabular}

calculated based on the Fenton growth chart, and neonates were classified as SGA, AGA, LGA [8].

Women recruited into the study self-reported their pre-pregnancy and delivery weight. The interviewer verified the self-reported data with the data given upon admission to the hospital and recorded during prenatal visits in the patient's prehospitalization pregnancy documents. This minimized the risk of recall bias. Only women who agreed to a urogynecological exam participated in the study, which may be a selection bias source.

The STROBE guideline was used as a reporting guideline to ensure a clear and complete report of the study's design, conduct, and findings. The study was approved by the Centre of Postgraduate Medical Education Bioethics Committee (Decision No. 47/PB/2018). Patients consented to participation in the study.

\section{Statistical methods}

The data was analyzed using Dell Inc. (2016). Dell Statistica (data analysis software system), version 13, and R Statistical Software (Foundation for Statistical Computing, Vienna, Austria). Shapiro-Wilk test confirmed compliance with a normal distribution. Qualitative data were presented as frequency (percentage). Group comparison was performed using ANOVA type Kruskal-Wallis test. For statistically significant results, posthoc tests of Multiple Rank Average Comparisons were done. Quantitative data correlations were checked using rho-Spearman. To compare quantitative data in groups of women with and without diabetes Mann-Whitney $U$ test was used. Differences in GWG calculated by the two methods were assessed with the multinominal test. The level of statistical significance was assumed as $p<0.05$.

\section{RESULTS}

Eight thousand one hundred fifty-nine records were available for analysis. We excluded from the study preterm deliveries, pregestational diabetes, multiple deliveries, and incomplete data regarding weight and height $(n=339)$. In the final analysis, there were 7820 complete records.

The characteristics of the study population are presented in Table 2. The average age of the surveyed women was 31.22 (SD 4.36) years. There were no significant differences between the mean age in the studied groups. Most patients were primiparas $(41.62 \%)$, para two $(36.45 \%)$, para three (13.50\%), and para four (8.43\%) comprised the rest of the respondents. BMI increased with parity $(p=0.000)$. The posttest showed that BMI increases significantly between para 1 and 3. In para more than 3, there are no significant differences. But GWG does not change significantly with each subsequent birth.

Among women in the studied group, 27.44 had hypothyroidism, and $7.44 \%$ had pregnancy diabetes. Overweight and obese women had a significantly higher incidence of GDM (13.38\% and $29.03 \%$, respectively). The average birth weight was 3472 grams and differed considerably depending on maternal BMI. The largest average neonatal birth weight was observed in overweight and obese mothers (3578 and 3548 grams, respectively). Children of underweight mothers had the lowest average birth weight (3327 grams). In the studied group, there was a slightly higher number of boys than girls. BMI did not affect fetal sex (Tab. 2).

The average pregnancy weight gain was $14.23 \mathrm{~kg}$, and the average weekly weight gain was $0.36 \mathrm{~kg}$. The values differed significantly depending on pre-pregnancy BMI (Tab. 3). Analysis of compliance of weight gain with IOM recommendations using method I showed that only $43.63 \%$ of women had weight gain in accordance with IOM guidelines (22.99\% - below; 33.32\% - above). Mostly in accordance with the recommendations were underweight (52\%) and normal weight (47\%) women. Among overweight and obese patients, only $25 \%$ were compliant with IOM. Above IOM guidelines were $68 \%$ of overweight and $56 \%$ of obese women. Below IOM guidelines were primarily underweight (37\%) and normal weight (24\%) women (Tab. 3).

An analogous analysis was performed using method II (Tab. 3). A multinomial test revealed that compliance differed significantly depending on the method used $(p<0.05)$.

The average weight gain in pregnancy is significantly $(p<0.001)$ lower in the group of women with diabetes than in women without diabetes. The most statistically significant difference $(3.44 \mathrm{~kg})$ is in the group of obese women and the smallest $(2.66 \mathrm{~kg})$ in the group of normal-weight women $(p<0.001)$ (Tab. 4).

Only $32 \%$ of all women with gestational diabetes were in accordance with IOM guidelines. Overweight and obese 


\begin{tabular}{|c|c|c|c|c|c|c|}
\hline Prepragnacy weight category & Underweight & $\begin{array}{l}\text { Normal } \\
\text { weight }\end{array}$ & Overweight & Obese & All & p \\
\hline $\mathrm{N}$ (\% of total) & $730(9.34)$ & $5885(75.26)$ & $957(12.24)$ & $248(3.17)$ & $7820(100)$ & \\
\hline Mean age (SD) & $30.45(4.55)$ & $31.22(4.28)$ & $31.71(4.50)$ & $31.65(4.65)$ & $31.22(4.36)$ & 0.000 \\
\hline $\begin{array}{l}\text { GDM (\% of group) } \\
\text { GDM } 1 \\
\text { GDM } 2\end{array}$ & $\begin{array}{l}46(6.30) \\
40(5.48) \\
6(0.82)\end{array}$ & $\begin{array}{l}336(5.71) \\
275(4.67) \\
61(1.04)\end{array}$ & $\begin{array}{l}128(13.38) \\
86(8.99) \\
42(4.39)\end{array}$ & $\begin{array}{l}72(29.03) \\
36(14.52) \\
36(14.52)\end{array}$ & $\begin{array}{l}582(7.44) \\
437(5.59) \\
145(1.85)\end{array}$ & $\begin{array}{l}0.000 \\
0.000 \\
0.000\end{array}$ \\
\hline Hypothyroidism (\% of group) & $215(29.45)$ & $15.65(26.59)$ & $279(29.15)$ & $87(35.08)$ & $2146(27.44)$ & 0.065 \\
\hline Pregnancy hypertension (\% of group) & $7(0.96)$ & $83(1.41)$ & $46(4.81)$ & $24(9.86)$ & $160(2.05)$ & 0.000 \\
\hline Prepregnancy hypertension (\% of group) & $3(0.41)$ & $16(0.05)$ & $11(0.31)$ & $11(1.21)$ & $41(0.52)$ & 0.000 \\
\hline $\begin{array}{l}\text { Parity (\% of group) } \\
1 \\
2 \\
3 \\
4 \\
>4\end{array}$ & $\begin{array}{l}328(44.93) \\
268(36.71) \\
83(11.37) \\
35(4.80) \\
16(2.19)\end{array}$ & $\begin{array}{l}2476(42.07) \\
2142(36.40) \\
801(13.61) \\
302(5.13) \\
164(2.79)\end{array}$ & $\begin{array}{l}357(37.31) \\
346(36.15) \\
140(14.63) \\
63(6.58) \\
51(5.33)\end{array}$ & $\begin{array}{l}94(37.90) \\
94(37.90) \\
32(12.90) \\
13(5.24) \\
15(6.06)\end{array}$ & $\begin{array}{l}3255(41.62) \\
2850(36.45) \\
1056(13.50) \\
413(5.28) \\
246(3.15)\end{array}$ & 0.001 \\
\hline Mean Birth weight (SD) [gr] & 3327 (394) & $3470(418)$ & $3578(431)$ & $3548(433)$ & $3472(422)$ & 0.000 \\
\hline $\begin{array}{l}\text { FENTON (\% of group) } \\
\text { SGA } \\
\text { AGA } \\
\text { LGA }\end{array}$ & $\begin{array}{l}70(9.58) \\
648(88.77) \\
12(1.64)\end{array}$ & $\begin{array}{l}307(5.22) \\
5272(89.58) \\
306(5.20)\end{array}$ & $\begin{array}{l}32(3.34) \\
828(86.52) \\
97(10.14)\end{array}$ & $\begin{array}{l}9(3.63) \\
208(83.87) \\
31(12.50)\end{array}$ & $\begin{array}{l}418(5.35) \\
6956(88.95) \\
446(5.70)\end{array}$ & 0.000 \\
\hline $\begin{array}{l}\text { Gender (\% of group) } \\
\text { Male } \\
\text { Female }\end{array}$ & $\begin{array}{l}368(50.41) \\
362(49.59)\end{array}$ & $\begin{array}{l}3034(51.55) \\
2851(48.45)\end{array}$ & $\begin{array}{l}500(52.25) \\
457(47.75)\end{array}$ & $\begin{array}{l}118 \text { (47.58) } \\
130(52.42)\end{array}$ & $\begin{array}{l}4020(51.41) \\
3800(48.59)\end{array}$ & 0.5336 \\
\hline
\end{tabular}

SD — standard deviation; GDM — gestational diabetes; SGA — small-for-gestational-age; AGA — appropriate-for-gestational-age; LGA — large-for-gestational-age

Table 3. Compliance with weight gain recommendations (methods I and II)

\begin{tabular}{|c|c|c|c|c|c|c|}
\hline Prepragnacy weight category & Underweight & $\begin{array}{l}\text { Normal } \\
\text { weight }\end{array}$ & Overweight & Obese & All & $\mathbf{p}$ \\
\hline Mean weight gain (SD) [kg] & $13.82(4.06)$ & $14.51(4.37)$ & $13.81(5.49)$ & $10.28(7.02)$ & $14.23(4.66)$ & 0.000 \\
\hline Mean weight gain per week (SD) [kg] & $0.35(0.10)$ & $0.37(0.11)$ & $0.35(0.14)$ & $0.26(0.18)$ & $0.36(0.12)$ & 0.000 \\
\hline \multicolumn{7}{|l|}{ METHOD I } \\
\hline $\begin{array}{l}\text { Women with weight gain below recommended } \\
\text { (\% of group) }\end{array}$ & $274(37.54)$ & $1408(23.92)$ & $70(7.31)$ & $46(18.55)$ & $1798(22.99)$ & 0.000 \\
\hline $\begin{array}{l}\text { Women with weight gain compliant to } \\
\text { recommended (\% of group) }\end{array}$ & $376(51.50)$ & $2742(46.60)$ & $236(24.66)$ & $62(25.00)$ & $3416(43.68)$ & \\
\hline $\begin{array}{l}\text { Women with eight gain above recommended (\% } \\
\text { of group) }\end{array}$ & $80(10.96)$ & $1735(29.48)$ & $651(68.03)$ & $140(56.45)$ & $2606(33.32)$ & \\
\hline \multicolumn{7}{|l|}{ METHOD II } \\
\hline $\begin{array}{l}\text { Women with weight gain below recommended } \\
\text { (\% of group) }\end{array}$ & $254(34.80)$ & $1336(22.70)$ & $71(7.42)$ & $48(19.36)$ & $1709(21.85)$ & 0.000 \\
\hline $\begin{array}{l}\text { Women with weight gain compliant to } \\
\text { recommended (\% of group) }\end{array}$ & $380(52.05)$ & $2533(43.05)$ & $221(23.09)$ & $55(22.17)$ & 3189 (40.78) & \\
\hline $\begin{array}{l}\text { Women with weight gain above recommended } \\
\text { (\% of group) }\end{array}$ & $96(13.15)$ & $2016(34.25)$ & $665(69.49)$ & $145(58.47)$ & $2922(37.37)$ & \\
\hline
\end{tabular}

SD - standard deviation

Table 4. Mean weight gain women with and without gestational diabetes

\begin{tabular}{|l|l|l|l|}
\hline Mean weight gain women (SD) $[\mathbf{k g}]$ & Without GDM & With GDM & $\mathbf{p}$ \\
\hline All women & $14.47(4.53)$ & $11.19(5.24)$ & 0.00 \\
\hline Underweight women & $14.01(3.99)$ & $10.96(4.08)$ & 0.00 \\
\hline Normal Weight women & $14.66(4.31)$ & $12.00(4.61)$ & 0.00 \\
\hline Overweight women & $14.25(5.36)$ & $11.00(5.58)$ & 0.00 \\
\hline Obese women & $11.28(6.95)$ & $7.84(6.63)$ & 0.00 \\
\hline
\end{tabular}

SD - standard deviation; GDM — gestational diabetes 


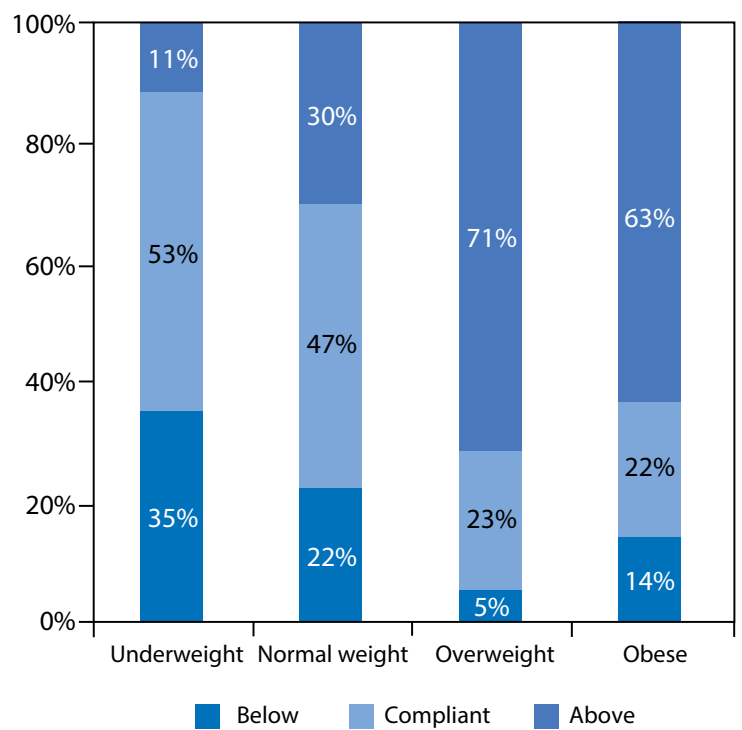

Figure 1. Compliance to weight gain recommendations - women without gestational diabetes (method I)

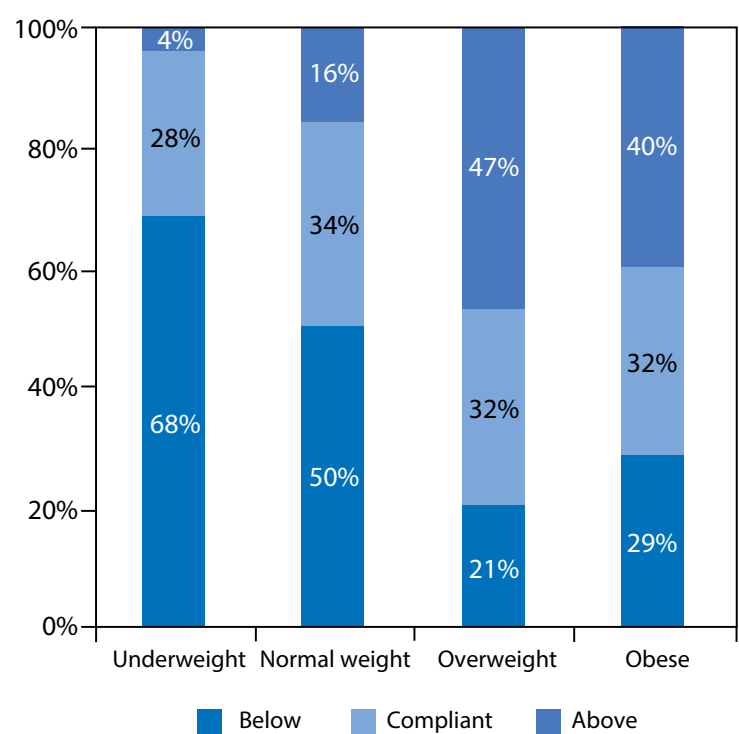

Figure 2. Compliance to weight gain recommendations - women with gestational diabetes (method I)

\begin{tabular}{|l|l|l|l|l|}
\hline \multicolumn{2}{|c|}{ Table 5. Mean birth weight depending on the pre-pregnancy body mass index and compliance to Institute of Medicine } \\
\hline Mean birth weight (SD) [gr] & $\begin{array}{l}\text { Women with weight gain } \\
\text { below recommended }\end{array}$ & $\begin{array}{l}\text { Women with weight gain } \\
\text { compliant with recommended }\end{array}$ & $\begin{array}{l}\text { Women with weight gain } \\
\text { above recommended }\end{array}$ & p \\
\hline Underweight women & 3230 & 3353 & 3481 & 0.000 \\
\hline Normal weight women & 3334 & 3457 & 3601 & 0.000 \\
\hline Overweight women & 3435 & 3549 & 3603 & 0.055 \\
\hline Obese women & 3528 & 3458 & 3589 & 0.135 \\
\hline
\end{tabular}

SD — standard deviation

women with diabetes are more likely to comply with IOM than women without diabetes. In contrast, women with normal weight and underweight with diabetes are less likely to achieve IOM weight gain in pregnancy than women without diabetes. More women classify below the recommended GWG and less above the recommended GWG than women without diabetes (Fig. 1 and Fig. 2).

Spearman's correlation showed a statistically significant but weak relationship between pregnancy weight gain and neonatal birthweight ( $R s=0.23 ; p<0.05)$. In all pre-pregnancy weight categories, the correlation results were statistically significant. Weak correlation occurred in the normal weight ( $R s=0.25)$ and underweight $(R s=0.28)$ groups. In the overweight and obese groups, the correlation was very weak.

Comparing the GWG and neonatal birthweight showed that the birthweight differed significantly depending on compliance to weight gain recommendations in the underweight and normal-weight group. In these two groups, women with weight gain below recommended GWG gave birth to significantly smaller children than women with normal and above recommended GWG (Tab. 5). Women with diabetes gave birth to significantly $(p<0.001)$ smaller children ( $M=3399 \mathrm{~g}$ ) than women without diabetes $(\mathrm{M}=3479 \mathrm{~g})$.

Underweight women are significantly more likely to give birth to SGA neonates. In contrast, obese and overweight women are significantly more likely to give birth to LGA neonates (12\% - obese, $10 \%$ - overweight) (Tab. 1). Women who have GWG below recommendations significantly more often give birth to SGA neonates, and women who exceeded GWG standards significantly more often give birth to LGA neonates. Simultaneously, 2-3\% of women with excess weight gain gave birth to SGA neonates, and those that gained below recommendations gave birth to LGA neonates. (Tab. 6)

\section{DISCUSSION}

WHO report from 2019 ranks Poland 85th in the world, with $23.1 \%$ of the population classified as obese. The USA 
Table 6. Accordance with Institute of Medicine guidelines vs small-for-gestational-age/appropriate-for-gestational-age/large-for-gestational-age

\begin{tabular}{|l|l|l|l|l|l|}
\hline & $\begin{array}{l}\text { Women with weight gain } \\
\text { below recommended } \\
\mathbf{n}=\mathbf{1 7 0 9}(\%)\end{array}$ & $\begin{array}{l}\text { Women with weight gain } \\
\text { compliant to recommended } \\
\mathbf{n = 3 1 8 9}(\%)\end{array}$ & $\begin{array}{l}\text { Women with weight gain } \\
\text { above recommended } \\
\mathbf{n = 2 9 2 2}(\%)\end{array}$ & $\begin{array}{l}\text { ALL } \\
\mathbf{n}=\mathbf{7 8 2 0}(\%)\end{array}$ & $\mathbf{p}$ \\
\hline SGA & $149(8.72)$ & $185(5.80)$ & $84(2.87)$ & $418(5.35)$ & 0.000 \\
\hline AGA & $1523(89.12)$ & $2874(90.12)$ & $2560(87.61)$ & $6956(88.95)$ & \\
\hline LGA & $37(2.17)$ & $130(4.08)$ & $278(9.51)$ & $446(5.70)$ & \\
\hline
\end{tabular}

SGA — small-for-gestational-age; AGA — appropriate-for-gestational-age; LGA — large-for-gestational-age

is ranked 18 th, with $36.2 \%$ of obese adults $[2,9]$. In Poland's published data of the General Office of Statistics (GUS) in $2014,16.7 \%$ of adults were obese and $36.6 \%$ overweight adults. $15.6 \%$ of women were obese, according to GUS [10].

According to the NCD Risk Factor Collaboration (NCD-RisC), 3 out of 5 adult citizens in Poland are overweight, and one out of four is obese. The scale of the problem is increasing. The prognosis is that by $202525.9 \%$ of women will be obese, a $10 \%$ increase to the current statistics [11].

From a European perspective, Poland ranks $11^{\text {th }}$ among 20 European countries included in the cohort studied by Marques et al., 34814 participants had BMI calculated and ranked. The highest prevalence of overweight women was in Czech (45.2\%), Hungary (43.7\%), and Lithuania (41.7\%). Obesity was most prevalent in Slovenia (20.8\%), Estonia (19.7\%) and Great Britain (19.2\%) [12].

With the growing prevalence of overweight and obesity in our study population, we have observed insufficient adherence to the IOM guidelines, especially by overweight women. In our study, $15.51 \%$ of patients were overweight or obese. Obese women were $3.17 \%$ of the group. This number, which is smaller than the country's reported obesity rate, can be explained by the fact that obese women with a $\mathrm{BMI}>35$ have a higher infertility rate than normal-weight women [13]. Overweight and obese women accounted for $42.41 \%$ of GDM. Interestingly these women with GDM had much better adherence to IOM guidelines than overweight and obese women without GDM, which shows how an intervention such as diet can affect GWG [14]. Surprisingly, the highest number of women that classified as above IOM recommendations was among overweight women without GDM. The same results for GWG among overweight and obese women were obtained in the study by Zhao et al. [15], (Chinese population). In contrast, Thapa \& Paneru presented that $57 \%$ of overweight women had GWG consistent with the IOM (Nepalese population, small study, 227 women) [16]. Similar results were published by Diemert et al. [17]. The fact that overweight women are more at risk of not fitting the IOM guidelines was a result that differed from our initial hypothesis. This is a group of women where there is the highest potential for intervention. Since in our study $\mathrm{BMI}$ increased with parity, these are women that could be at risk of being obese in subsequent pregnancies. This shows that education regarding GWG among overweight patients without GDM is currently insufficient $[5,18]$. Since GWG does not increase in parity in this study, the greatest threat is not returning to pre-pregnancy weight between pregnancies.

A meta-analysis showed that mothers are motivated to take measures that could affect their child's wellbeing but are not always aware of the importance of GWG on children's health. Therefore, it is necessary to educate women in this area by doctors and midwives, although this analysis has shown this task a difficult task because it is a sensitive topic [19].

Adjusting pregnancy duration in term pregnancies (37-40 weeks) does not significantly affect adherence to IOM guidelines rendering only a $2 \%$ difference between the two methods. We tested two methods of calculating GWG. The application of method II resulted in fewer patients fitting in the recommended guidelines. This arises from the fact that more than $50 \%$ delivered before 40 weeks' gestation. In every group, two percent more cases did not fit in the recommended guidelines. In their original paper, Gilmore and Redman showed a $40 \%$ change in the qualification of adherence to IOM guidelines after correcting for gestational age. This could result from their model being a theoretical one and was not tested on either retrospective or a prospective population [1]. Perhaps if this analysis were made for preterm deliveries, the difference would be more significant. This aspect needs further assessment.

Finally, we looked at the relationship between pre-pregnancy BMI and GWG and birth weight. Pre-pregnancy BMI and excess GWG are risk factors for macrosomia [20, 21]. Previous reports have concentrated on SGA, AGA, and LGA rates related to $B M I$ and GWG [14]. Similarly, there was a correlation between increased BMI and GWG and LGA and decreased BMI and GWG and SGA in this study. An interesting group of patients in the neonatal outcome would be the $2-3 \%$ of SGA in obese women and LGA in underweight women. This combination warrants further research. Although, it suggests that other factors are affecting fetal growth. We found a weak correlation between gestational weight gain and neonatal birth weight in the context of birthweight itself. But being below IOM guidelines in un- 
derweight and normal-weight women affected neonatal birthweight. These neonates were statistically smaller in this group.

Interestingly this effect was not observed at all in obese women. Identical results published Thapa and Paneru [16]. Compared to pre-pregnancy BMI that is confirmed to correlate with neonatal birthweight - our study confirms conclusions from previous studies based on IOM [15, 16, 22].

This study presents a large group of pregnant women that have self-reported their pregnancy-related weight. This allowed for the assessment of GWG and verification of the two methods of calculation. Secondly, we showed how the diagnosis of GDM and the medical care that follows, including diet, affects GWG and its correlation with fitting the IOM guidelines - leading to the conclusion that in most GDM women, the IOM guidelines underestimate GWG. Perhaps there should be separate GWG guidelines for women with diabetes.

This was a weight self-reported retrospective study, making it a potential for bias. There is a risk of recall and reporting bias for self-reported pregnancy related weight. Fortunately, previous studies have shown that this risk is not that significant [23]. Phelan et al. [24] showed a high level of agreement between self-reported preconception weight and available clinical record of preconception weight gathered in the last year. According to a systematic review published by Headen et al. [25], although measured weight is preferable, self-report is a cost-effective and practical measurement approach. They point out the need to develop bias correction techniques for self-reported pregnancy-related weight. We could not analyze adverse perinatal outcomes due to the risk of selection bias. Women that participated in the study were women that consented to a postpartum urogynecological examination. These were primarily women that delivered vaginaly. For this reason, the study only included women in term pregnancies $>37$ weeks gestation. To reach the study's aims, the discussed sources of selection bias have potentially little effect on the investigation results.

\section{CONCLUSIONS}

Less than half of women had GWG within the recommended norms. Statistically significant differences were found in methods of calculation of GWG, but it was not found clinically significant. Correction for pregnancy duration when calculating GWG reclassifies two percent of patients. Being below or above the recommended GWG resulted in an increased risk of SGA and LGA, respectively. We underestimate the risk of crossing the line between overweight and obesity during pregnancy. Both patients and medical professionals should be educated on calculating pre-pregnancy BMI and goals for GWG during pregnancy.

\section{Acknowledgment}

St. Sophia's Obstetrics and Gynecological Hospital for providing the database of hospitalized patients.

\section{Statement of ethics}

The study was approved by the Centre of Postgraduate Medical Education Bioethics Committee (Decision No. $47 / \mathrm{PB} / 2018$ ). Patients consented to participation in the study.

\section{Conflict of interests}

The authors have no conflicts of interest to declare.

\section{Funding}

This study was funded by the Centre of Postgraduate Medical Education Grant No. 501-1-081-34-20.

\section{REFERENCES}

1. Gilmore LA, Redman LM. Weight gain in pregnancy and application of the 2009 IOM guidelines: toward a uniform approach. Obesity (Silver Spring). 2015; 23(3): 507-511, doi: 10.1002/oby.20951, indexed in Pubmed: 25521748.

2. Most Obese Countries 2019. http://worldpopulationreview.com/countries/most-obese-countries/ (2019-11-16).

3. Blüher M. The distinction of metabolically 'healthy' from 'unhealthy' obese individuals. Current Opinion in Lipidology. 2010; 21(1): 38-43, doi: $10.1097 / \mathrm{mol} .0 \mathrm{~b} 013 \mathrm{e} 3283346 \mathrm{ccc}$.

4. O'Reilly J, Reynolds R. The risk of maternal obesity to the long-term health of the offspring. Clinical Endocrinology. 2012; 78(1): 9-16, doi: 10.1111/cen.12055.

5. Kominiarek M, Peaceman A. Gestational weight gain. American Journal of Obstetrics and Gynecology. 2017; 217(6): 642-651, doi: 10.1016/j. ajog.2017.05.040.

6. Nutrition During Pregnancy. 1990, doi: 10.17226/1451.

7. Weight Gain During Pregnancy. 2009, doi: 10.17226/12584.

8. Fenton T, Kim J. A systematic review and meta-analysis to revise the Fenton growth chart for preterm infants. BMC Pediatrics. 2013; 13(1), doi: 10.1186/1471-2431-13-59.

9. Fattest Country in The World: What is the Most Obese Country? https:// www.who.com (2019-11-16).

10. GUS. Zdrowie i zachowanie zdrowotne mieszkańców Polski w świetle Europejskiego Ankietowego Badania Zdrowia (EHIS) 2014 r. 2015.

11. Departament analiz i strategii, Narodowy Fundusz Zdrowia. Cukier, otyłość — konsekwencje. Przegląd literatury, szacunki dla Polski. ; 2018.

12. Marques $A$, Peralta $M, N a i a ~ A$, et al. Prevalence of adult overweight and obesity in 20 European countries, 2014. European Journal of Public Health. 2017; 28(2): 295-300, doi: 10.1093/eurpub/ckx143.

13. Ruager-Martin R, Hyde MJ, Modi N. Maternal obesity and infant outcomes. Early Hum Dev. 2010; 86(11): 715-722, doi: 10.1016/j.earlhumdev.2010.08.007, indexed in Pubmed: 20846795.

14. Santos $S$, Voerman $E$, Amiano $P$, et al. Impact of maternal body mass index and gestational weight gain on pregnancy complications: an individual participant data meta-analysis of European, North American, and Australian cohorts. BJOG: An International Journal of Obstetrics \& Gynaecology. 2019, doi: 10.1111/1471-0528.15661.

15. Zhao $\mathrm{R}, \mathrm{Xu} \mathrm{L}, \mathrm{Wu} \mathrm{ML}$, et al. Maternal pre-pregnancy body mass index gestational weight gain influence birth weight. Women and Birth. 2018; 31(1): e20-e25, doi: 10.1016/j.wombi.2017.06.003.

16. Thapa M, Paneru R. Gestational Weight Gain and its Relation with Birth Weight of the Newborn. JNMA J Nepal Med Assoc. 2017; 56(207): 309-313, indexed in Pubmed: 29255311.

17. Diemert A, Lezius S, Pagenkemper $M$, et al. Maternal nutrition, inadequate gestational weight gain and birth weight: results from a prospective birth cohort. BMC Pregnancy Childbirth. 2016; 16: 224, doi: 10.1186/s12884-016-1012-y, indexed in Pubmed: 27528213. 
18. Aiken C, Hone L, Murphy HR, et al. Improving outcomes in gestational diabetes: does gestational weight gain matter? Diabetic Medicine. 2018; 36(2): 167-176, doi: 10.1111/dme.13767.

19. Tian C, Hu C, He X, et al. Excessive weight gain during pregnancy and risk of macrosomia: a meta-analysis. Archives of Gynecology and Obstetrics. 2015; 293(1): 29-35, doi: 10.1007/s00404-015-3825-8.

20. Yang W, Han F, Gao X, et al. Relationship Between Gestational Weight Gain and Pregnancy Complications or Delivery Outcome. Scientific Reports. 2017; 7(1), doi: 10.1038/s41598-017-12921-3.

21. Vieira C, Sarabando R, Teixeira N, et al. Impact of gestational weight gain on obstetric outcomes. European Journal of Obstetrics \& Gynecology and Reproductive Biology. 2019; 234: e71, doi: 10.1016/j. ejogrb.2018.08.312.
22. Du Mk, Ge Ly, Zhou Ml, et al. Effects of pre-pregnancy body mass index and gestational weight gain on neonatal birth weight. Journal of Zhejiang University-SCIENCE B. 2017; 18(3): 263-271, doi: 10.1631/jzus.b1600204.

23. Lin C, DeRoo L, Jacobs $S$, et al. Accuracy and reliability of self-reported weight and height in the Sister Study. Public Health Nutrition. 2011; 15(6): 989-999, doi: 10.1017/s1368980011003193.

24. Phelan S, Phipps M, Abrams B, et al. Randomized trial of a behavioral intervention to prevent excessive gestational weight gain: the Fit for Delivery Study. The American Journal of Clinical Nutrition. 2011; 93(4): 772-779, doi: 10.3945/ajen.110.005306.

25. Headen I, Cohen AK, Mujahid M, et al. The accuracy of self-reported pregnancy-related weight: a systematic review. Obesity Reviews. 2017; 18(3): 350-369, doi: 10.1111/obr.12486. 